\title{
PENYULUHAN BRISK WALKING TERHADAP PENURUNAN KADAR GULA DARAH PADA PASIEN DIABETES MELITUS
}

\section{Pratiwi Christa Simarmata ${ }^{1}$, Kardina Hayati $^{2}$, Sari Desi Esta Ulina Sitepu ${ }^{3}$, Ruttama Hutahuruk ${ }^{1}$, Rita Ayu Butar Butar ${ }^{1}$, Nilam Cahya ${ }^{4}$

\author{
${ }^{1}$ Program Studi Keperawatan S1, Institut Kesehatan Medistra Lubuk Pakam \\ ${ }^{2}$ Program Studi Pendidikan Profesi Ners, Institut Kesehatan Medistra Lubuk Pakam \\ ${ }^{3}$ Program Studi Keperawatan D3, Institut Kesehatan Medistra Lubuk Pakam \\ ${ }^{4}$ Fakultas Keperawatan dan Fisioterapi, Institut Kesehatan Medistra Lubuk Pakam
}

\author{
JIn. Sudirman No.38 Lubuk Pakam, Kabupaten Deli Serdang, \\ Sumatera Utara - Indonesia \\ *email korespondensi author: pratiwisimarmata92@gmail.com
}

DOI $10.35451 / j p k . v 1 i 1.743$

\begin{abstract}
Abstrak
Diabetes melitus disebabkan insulin tidak lagi tercukupi dalam tubuh serta insulin tidak dapat digunakan dalam memenuhi kebutuhan tubuh. Diabetes melitus dapat menjadi serius dan mebahayakan jika tidak segera diobati. Pengontrolan kadar glukosa darah melalui aktifitas fisik masih sulit dilakukan disebabkan kedaran masyarakat yang kurang. Aktifitas fisik termasuk dalam pilar penatalaksanaan komplikasi diabetes melitus. Aktifitas fisik dapat dilakukan dengan brisk walking. Hal ini jika dilakukan secara teratur dapat merangsang sintesis glikogen melalui peningkatan aksi insulin dan merangsang transportasi glukosa. Tujuan pengabdian masyarakat ini untuk memberikan penyuluhan tentang Brisk Walking terhadap perubahan nilai glukosa dalam darah pada pasien diabetes mellitus. Metode kegiatan dilakukan dengan tahapan dimulai dari penyampaian materi kepada penderita diabetes melitus tentang konsep penyakit diabetes melitus dan penatalaksanaannya, pemeriksaan nilai glukosa darah dan evaluasi hasil pelaksanaan. Adapun hasil dari kegiatan pengabdian masyarakat ini adalah menjadi bahan kajian untuk di diskusikan agar peserta lebih paham dan secara diri mampu mengendalikan terjadinya komplikasi yang dapat diakibatkan diabetes melitus.
\end{abstract}

Kata kunci: penyuluhan, brisk walking, diabetes melitus

\begin{abstract}
Diabetes mellitus is caused by insufficient insulin in the body and insulin cannot be used to meet the body's needs. Diabetes mellitus can be serious and dangerous if not treated immediately. Controlling blood glucose levels through physical activity is still difficult to do due to lack of public awareness. Physical activity is included in the pillars of the management of complications of diabetes mellitus. Physical activity can be done by brisk walking. This if done regularly can stimulate glycogen synthesis through increasing insulin action and stimulating glucose transport. The purpose of this community service is to provide counseling about Brisk Walking on changes in blood glucose values in patients with diabetes mellitus. The method of activity is carried out in stages starting from delivering material to people with diabetes mellitus about the concept of diabetes mellitus and its management, checking blood glucose values and evaluating the results of the implementation. The results of this community service activity are used as study material to be discussed so that participants can better understand and be able to control the occurrence of complications that can be caused by diabetes mellitus.
\end{abstract}


Received: 15 June 2021 :: Accepted: 17 June 2021 :: Published: 30 June 2021

Keywords: counseling, brisk walking, diabetes mellitus

\section{Pendahuluan}

The silent killer sebutan yang sering digunakan pada diabetes melitus, sebab diabetes melitus dapat mengenai semua organ tubuh tanpa terkecuali. Diabetes melitus disebabkan insulin tidak lagi tercukupi dalam tubuh serta insulin tidak dapat digunakan tubuh untuk memenuhi kebutuhan (IDF, 2014). Penumpukan glukosa dalam darah disebabkan insulin yang tidak diproduksi, sehingga tidak dapat masuk ke dalam sel. Glukosa masuk ke dalam darah merupakan fungsi dari insulin (WHO, 2016).

Penderita diabetes melitus diseluruh dunia mencapai angka 422 juta jiwa, dengan 1,6 juta kematian secara langsung setiap tahunnya. (WHO, 2016). Pada tahun 2030 diperkirakan jumlah yang terdiagnosis diabetes melitus mencapai 12 juta jiwa. $\mathrm{Hal}$ ini berkaitan dengan pertumbuhan jumlah penduduk, bertambahnya usia lanjut, perpindahan tempat tinggal serta gaya hidup yang pada kemungkinannya menyebabkan peningkatan angka diabetes melitus di seluruh dunia sebesar $55 \%$ pada tahun 2035 .

Pengelolaan diabetes melitus diawali dengan penatalaksanaan bersifat non farmakologis, seperti perencanaan makanan dan latihan fisik. Perencanaan makanan dapat dilakukan dengan membuat daftar diit, sedangkan latihan fisik dilakukan dengan aktivitas fisik seperti jalan kaki, bersepeda, santai, dan berenang. Adapun tujuan dari pengelolaan diabetes pada penderita diabetes melitus bertujuan dalam menjaga kadar glukosa darah tetap dalam rentang normal.

Brisk walking atau jalan cepat pada penderita diabetes melitus merupakan salah satu penatalaksaan yang mudah dilakukan sebab dapat dilakukan dimana saja terutama di luar rumah (Ana dan Anita, 2017). Brisk walking selain bermanfaat dalam menjaga kadar glukosa darah, juga bermanfaat dalam menurunkan resiko komplikasi diabetes melitus, penyakit jantung dan stroke (Darwin \& Reni,
2013). Brisk walking merupakan salah satu latihan aerobic yang dianjurkan pada penderita diabetes melitus (Regina, 2016).

Penelitian Listyani \& Fadilah (2017) menyatakan setelah dilakukan brisk walking kadar glukosa darah penderita diabetes melitus mengalami penurunan rata-rata 19,26 $\mathrm{mg} / \mathrm{dl}$. Sedangkan penelitian yang dilakukan Putri (2016) menyatakan brisk walking dapat mengontrol kadar gula darah, dengan perlakukan 20-30 menit sebanyak 3 kali seminggu. Penelitian Lukman Fauzi (2013) didapati intensitas jalan kaki cepat didapati rata-rata penurunan kadar glukosa darah sebesar $37,75 \mathrm{mg} / \mathrm{dl}$ terhadap 12 responden.

Berdasarkan latar belakang diatas, maka penulis tertarik untuk melakukan Penyuluhan Brisk Walk terhadap Penurunan Kadar Glukosa Darah pada Pasien Diabetes Melitus.

\section{Metode}

Kegiatan ini dilakukan di RS Grandmed Lubuk Pakam pada bulan Mei 2021. Sasaran dari pengabdian masyarakat ini adalah penderita diabetes melitus berjumlah 30 orang. Metode yang digunakan dalam pengabdian masyarakat ini adalah pemberian edukasi atau penyuluhan kepada penderita diabetes melitus terkait brisk walking yang dapat menurunkan kadar glukosa dalam darah serta mengkontol dan menstabilkannya. Media yang digunakan Power point presentation (PPT) dan LCD selama kurang lebih 90 menit. Untuk mengukur keberhasilan edukasi atau penyuluhan yang diberikan dilakukan pengukuran pengetahuan sebelum dan sesudah edukasi atau penuluhan dengan menggunakan kuesioner.

\section{Hasil dan Pembahasan Hasil}

Tabel 1. Distribusi Frekuensi dan Persentase Karakteristik Responden $(n=30)$

No Jenis Kelamin $\quad$ F $\%$


Received: 15 June 2021 :: Accepted: 17 June 2021 :: Published: 30 June 2021

\begin{tabular}{cccc}
\hline 1 & Perempuan & 17 & 56,7 \\
2 & Laki-laki & 13 & 43,3 \\
\hline & Total & 30 & 100 \\
\hline
\end{tabular}

Sumber : Data Primer

Tabel 2. Distribusi Frekuensi dan

Persentase Karakteristik Responden Berdasarkan Usia $(n=30)$

\begin{tabular}{llcc}
\hline No & \multicolumn{1}{c}{ Usia } & F & \% \\
\hline 1 & $\begin{array}{l}\text { Dewasa Akhir (36- } \\
\text { 45 tahun) }\end{array}$ & 9 & 30 \\
2 & $\begin{array}{l}\text { Lansia Awal (46-55 } \\
\text { tahun) }\end{array}$ & 11 & 36,7 \\
3 & $\begin{array}{l}\text { Lansia Akhir (56-65 } \\
\text { tahun) }\end{array}$ & 8 & 26,6 \\
4 & Manula (>65 tahun) & 2 & 6,7 \\
\hline & 30 & 100 \\
\hline
\end{tabular}

Sumber : Data Primer

Tabel 3. Distribusi Frekuensi dan

Persentase Karakteristik Responden

Berdasarkan Pemeriksaan Glukosa Darah Sewaktu $(n=30)$

\begin{tabular}{cccc}
\hline No & $\begin{array}{c}\text { Glukosa Darah } \\
\text { Sewaktu }\end{array}$ & F & \% \\
\hline 1 & $<200 \mathrm{mg} / \mathrm{dL}$ & 4 & 13,3 \\
2 & $>200 \mathrm{mg} / \mathrm{dL}$ & 26 & 86,7 \\
\hline & Total & 30 & 100 \\
\hline
\end{tabular}

Sumber : Data Primer

\section{Pembahasan}

Kegiatan pengabdian masyarakat dilaksanakan di Rumah Sakit Grandmed Lubuk Pakam. Kegiatan pengabdian masyarakat diawali dengan tahapan pemberian materi dan tanya jawab, selanjutnya dilakukan pemeriksaan kadar gula darah dan diakhiri dengan evaluasi. Adapun tahapannya sebagai berikut:

\section{Tahap pemberian materi}

Selama berlangsungnya kegiatan, peserta antusias mendengar materi yang disajikan karena persentase dilengkapi dengan foto-foto penyakit diabetes melitus. Media yang digunakan saat penyuluhan adalah Power point presentation (PPT) dan LCD selama kurang lebih 90 menit, dengan pembagian waktu 15 menit pembukaan, 45 menit penyampaian materi, dan 30 menit diskusi serta penutup. Pada saat penyuluhan, disampaikan pemberian materi tentang konsep penyakit diabetes melitus meliputi defenisi, tanda dan gejala, penyebab, faktor resiko, pemeriksaan penunjang, komplikasi, manajemen perawatan, dan penatalaksanaan non farmakologis terkhusus Brisk Walking.

\section{Tahap Pemeriksaan Kadar Gula Darah}

Tahap ini dilakukan untuk mengetahui kadar glukosa darah pada penderita diabetes melitus. Setelah dilakukan edukasi atau penyuluhan latihan brisk walking dilanjutkan dengan pemeriksaan kadar glukosa darah, serta konsultasi tentang hasil pemeriksaan dan hal yang dapat dilakukan dirumah terkait latihan aktifitas seperti brisk walking.

\section{Tahap Evaluasi}

Dari hasil pemeriksaan kadar glukosa darah sewaktu didapati kadar gula darah $<200 \mathrm{mg} / \mathrm{dL} 4$ orang $(13,3 \%)$ dan kadar gula darah $>200 \mathrm{mg} / \mathrm{dL}$ sebanyak 26 orang $(86,7 \%)$. Dari 4 orang responden dengan kadar gula darah $<200 \mathrm{mg} / \mathrm{dL}$ mengatakan mereka mengeluhkan sering buang air kecil pada malam hari, sering haus dan mengeluh sering lapar. Respon peserta nampak sangat antusias dan kegiatan berlangsung secara tertib dan baik. Aktivitas fisik yang teratur dapat mengendalikan nilai glukosa darah dan berat badan menjadi menurun (Sari, 2018). Penelitian Putri (2016), menyatakan latihan jasmani yang dilakukan 3 kali per minggu selama 30 menit dapat menurunkan resiko pada penderita diabetes melitus.

\section{Kesimpulan}

Pendidikan kesehatan secara terus-menerus tentang diabetes melitus adalah merupakan salah satu upaya yang cukup efektif untuk mencegah terjadinya komplikasi diabetes melitus lebih lanjut serta menurunkan angka kejadian diabetes melitus. Pendidikan kesehatan ini telah dilaksanakan pada Rumah Sakit Grandmed Lubuk Pakam dan dihadiri oleh 30 orang. Peserta 
nampak sangat antusias dan kegiatan berlangsung secara tertib dan baik. Didapati 4 orang responden dengan kadar gula darah $<200 \mathrm{mg} / \mathrm{dL}$ mengatakan mereka mengeluhkan sering buang air kecil pada malam hari, sering haus dan mengeluh sering lapar.

\section{Ucapan Terima Kasih}

Penulis ucapkan terima kasih kepada Direktur Rumah Sakit Grandmed Lubuk Pakam yang telah memberikan kesempatan kepada penulis untuk melakukan pengabdian masyarakat.

\section{Daftar Pustaka}

Ana dan Anita. (2017). Brisk Walking dapat menurunkan kadar glukosa darah penderita Diabetes Mellitus. Cendekia utama , 10-19.

Darwin \& Reni. (2013) Menikmati Gula Tanpa Rasa Takut. Jakarta: Sinar Ilmu

IDF. (2014). IDF diabetes atlas: Sixth edition. Retrieved from http://www.idf.org/sites/default/fil es/EN 6E Atlas Full 0.pdf

Listyarini, A. D. and Fadilah, A. (2017). Brisk Walking Dapat Menurunkan Kadar Glukosa Darah Pada Penderita Diabetes Mellitus Di Desa Klumpit Kecamatan Gebog Kabupaten Kudus. Jurnal Keperawatan dan Kesehatan Masyarakat Cendekia Utama, 6(2). doi: 10.31596/JCU.V6I2.187

Lukman. (2015). Kencing Manis (Diabetes Mellitus). Jakarta: Yayasan Pustaka Obor Indonesia.

Putri (2016). Hubungan Empat Pilar Pengendalian Dm Tipe 2 Dengan Rerata Kadar Gula Darah. Surabaya: Universitas Airlangga.

Regina, G. 2016. Olahraga untuk Penderita Diabetes. Diakses: 19 September 2016. http://diabetesmelitus.org/olahrag a-untuk-penderita-diabetes/

Sari. (2018). Pengaruh senam diabetes melitus terhadap kadar gula darah pada penderita diabetes melitus tipe 2. STIK, 35

World Health Organization (WHO). (2016). Diabetes, http://www.who.int/ mediacentre/ factsheets/ fs312. Updated January 2018 